\title{
Alternate Care Sites for COVID-19 Patients: Experience from the H144 Hospital of the Health Service of the Principality of Asturias, Spain
}

\author{
Rafael Castro Delgado; ${ }^{1,2}$ (1) Paloma Pérez Quesada; ${ }^{3}$ Eduardo Pintado García; ${ }^{4}$ Iñigo Marañón Zabalza; \\ Manuel Vallina-Victorero Vázquez; ${ }^{5}$ Rodrigo Escribano Balín ${ }^{4}$
}

1. Medical Director H144, Health Service of the Principality of Asturias, Oviedo (Spain)

2. Emergency and Disaster Research Unit, University of Oviedo, Oviedo (Spain)

3. Nursing Director H144, Health Service of the Principality of Asturias, Oviedo (Spain)

4. Engineer H144, Health Service of the Principality of Asturias, Oviedo (Spain)

5. Doctor H144, Health Service of the Principality of Asturias, Oviedo (Spain)

Correspondence:

Dr. Rafael Castro Delgado

SAMU-Asturias

Health Service of the Principality of Asturias Pza. Carbayón, 1. 33006 Oviedo (Spain)

E-mail: rafacastrosamu@yahoo.es

Conflicts of interest/funding: None declared. The authors have no financial or other interest that should be known to readers related to this document.

Keywords: COVID-19; field hospitals; pandemic; SARS-CoV-2; surge capacity

\section{Abbreviations:}

ACS: alternate care site

COVID-19: coronavirus disease 2019

FEMA: Federal Emergency Management Agency

HUCAB: Cabueñes University Hospital

ICU: intensive care unit

PCR: polymerase chain reaction

PPE: personal protective equipment

SELENE: Sespa's Electronic Health Record

System

WHO: World Health Organization

Received: June 16, 2021

Revised: August 6, 2021

Accepted: August 16, 2021

\begin{abstract}
Coronavirus disease 2019 (COVID-19) temporary hospitals, also called "alternate care sites" (ACS), as support to the health network have had uneven use. The World Health Organization (WHO) has published different recommendations in this regard. World-wide, many health services have improved their surge capacity with the implementation of new temporary hospital structures, but there have been few experiences of use over time despite representing an important element as support to the hospital network in the management of COVID-19 patients. In this article, the experiences are explained in the design, execution, and use of the temporary COVID-19 Hospital H144 of the Health Service of the Principality of Asturias (Sespa), with 144 beds, which was in operation from April 1 through July 1, 2020 (without admitting patients) and from November 12, 2020 through March 5, 2121, admitting a total of 334 COVID-19 patients (66\% women; $34 \% \mathrm{men}$ ) and generating 3,149 hospital stays. Maximum occupancy was 74 patients. Mean stay was 9.42 days $(\mathrm{MD}=3.99$; [1-34]). At discharge, 126 patients $(38 \%)$ went to a nursing home, 112 (33\%) to their home, 40 (12\%) were transferred to another hospital, and $56(17 \%)$ died. The mean age of the admitted patients was 82.79 years $(\mathrm{MD}=8.68$; [29-104]) and was higher in women (85.09; $\mathrm{MD}=7.57 ; \mathrm{P}=.000)$ than in men (78.28; $\mathrm{MD}=9.22)$. Some aspects to consider for future experiences of use have been: teamwork from different fields of knowledge (ie, architecture, engineering, medicine, and nursing) is essential for success; integration in the health system must be fully developed from different perspectives (ie, information system, logistics, medical records, or clinical procedures, among others); clear procedures for patient admission from different structures (ie, home, hospitals, nursing homes, or primary health care network) must combine with flexibility of use to adapt to new and unknown circumstances; and they must not compromise specialized staff availability in other health facilities.
\end{abstract}

Castro Delgado R, Pérez Quesada P, Pintado García E, Marañón Zabalza I, Vallina-Victorero Vázquez M, Escribano Balín R. Alternate care sites for COVID-19 patients: experience from the H144 hospital of the health service of the Principality of Asturias, Spain. Prehosp Disaster Med. 2021;36(6):774-781.

\section{Introduction}

The coronavirus disease 2019 (COVID-19) pandemic has stressed the health system in such a way that it has been necessary to reorganize part of its structure, human resources, and clinical approach. ${ }^{1}$ In disaster medicine, there is a widely used concept, "surge capacity," that could be defined as the capacity of the health system to expand its response capacity to needs that exceed normal demand. The COVID-19 pandemic has affected the entire integrity of the health system, which has led to talking about surge capacity for the entire health care

\section{doi:10.1017/S1049023X21001102}

(C) The Author(s), 2021. Published by Cambridge University Press on behalf of World Association for Disaster and Emergency Medicine. This is an Open Access article, distributed under the terms of the Creative Commons Attribution-NonCommercial-NoDerivatives licence (https://creativecommons.org/ licenses/by-nc-nd/4.0/), which permits non-commercial re-use, distribution, and reproduction in any medium, provided the original work is unaltered and is properly cited. The written permission of Cambridge University Press must be obtained for commercial re-use or in order to create a derivative work. 
system. This has led to the design of out-of-hospital structures, newly built following the classic concept of the World Health Organization (WHO; Geneva, Switzerland) "field hospital," or adapting civil facilities to be used as a hospital. Different guidelines define the fundamental aspects of their design and clinical operation. The US Federal Emergency Management Agency (FEMA; Washington, DC USA) developed the "Alternate Care Site [ACS] Toolkit." These ACS are defined in the US by FEMA and the Center for Disease Control and Prevention (CDC; Atlanta, Georgia USA) as "a building or structure of opportunity that is temporarily converted for health care use during a public health emergency to provide additional health capacity and capability for an affected community, outside the walls of a traditional established health care institution." Also, the WHO established recommendations for the design of temporary COVID-19 facilities ${ }^{4}$ and for the management of acute respiratory infections. ${ }^{5}$

Different types of structures were designed world-wide with different approaches regarding location (existing building or open areas) and design. 6,7 The H144 Hospital of the Health Service of the Principality of Asturias, Spain (Sespa) was built in the central pavilion of an exhibition hall. Gregg S. Meyer has described three interesting models of care in relation to temporary COVID-19 hospitals: ${ }^{8}$ (1) Acute Care Model, complex by focusing on intensive care, requiring highly specialized staff that could be needed from other intensive care units (ICUs); (2) Hospital Care Model, with a certain capacity for intensive care, wide availability of disciplines, and that tend to support an inadequate hospital network, also requiring a large number of staff in terms of their profiles; and (3) Non-Acute Care Model, for mild or recovering patients from other hospitals, allowing them to focus on moderate to severe COVID-19 patients and to increase their capacity to care for non-COVID-19 patients. This third model was adopted by the H144, and as Gregg S. Meyer points out, its strengths are low execution time and being easier to staff as it does not require high specialization, doesn't "absorb" specialized staff from other health centers, it improves the transition of hospitals to a non-pandemic phase, and can have a positive effect on the control of epidemic outbreaks in nursing homes. ${ }^{9}$

The Principality of Asturias is located in the north of Spain. It has 1,011,560 inhabitants with an elderly population and negative natural growth in recent years. The health system is organized in eight health areas, each with its reference hospital (Table 1). ${ }^{10}$

The aim of this article is to define the main challenges in the design, implementation, and operational aspects of ACS for COVID-19 patients following the experience of the H144 Hospital of the Health Service of the Principality of Asturias (Sespa), and describes the clinical activity during its operational time.

\section{Report}

Time Frame

Health systems managers in Asturias, on March 24, 2020, decided to create a new and temporary health facility to support the health care network in anticipation of a health care over-demand due to COVID-19 patients. The design was developed by the architect of the Health Department. On March 27, the first meeting of the medical direction with the architect took place to adapt the initial design to health care needs and organization. On March 28, the execution of the project began, ending on April 8. Medical direction approved its use to receive patients on April 9. Different fields of knowledge related to health worked on the project: medicine, nursing, hospital engineering, and hospital

\begin{tabular}{|l|c|}
\hline Public Hospitals & Beds \\
\hline Hospital de Jarrio & 105 \\
\hline Hospital Carmen y Severo Ochoa & 103 \\
\hline Hospital Universitario San Agustín & 436 \\
\hline Hospital Universitario Central de Asturias & 989 \\
\hline Hospital de Jove & 233 \\
\hline Hospital Universitario de Cabueñes & 457 \\
\hline Hospital del Oriente de Asturias & 90 \\
\hline Hospital Universitario Vital Álvarez Buylla & 176 \\
\hline Hospital Valle Nalón & 216 \\
\hline Associated Acute Care Hospitals & 90 \\
\hline Fundación Hospital de Avilés & 194 \\
\hline Hospital Monte Naranco & 120 \\
\hline Hospital Cruz Roja Española de Gijón & 148 \\
\hline Others & $\mathbf{3 , 3 5 7}$ \\
\hline Fundación Sanatorio Adaro & \\
\hline TOTAL ASTURIAS & \\
\hline
\end{tabular}

Castro Delgado @ 2021 Prehospital and Disaster Medicine

Table 1. Hospital Network of the Principality of Asturias

architecture (Figure 1). From July 1-10, the hospital was dismantled without having received patients.

In the beginning of a second wave, the Health Department decided to replicate the model again, with slight structural improvements, and construction began again on November 4 . On November 11, it was approved by the medical direction, and the first patient was received on November 12, 2020. On March 5, 2021, the last patient was discharged from H144 after 113 days of operation during the second and third wave, with 334 admitted patients and 3,149 hospital stays.

\section{Design, Construction, and Implementation of the H144}

The H144 hospital was placed in the central pavilion of Gijón Chamber of Commerce, located in the center of Gijón, Spain, with easy access control. The pavilion is an open-plan construction measuring approximately $89.70 \times 58.72$ meters and a height of almost 12 meters, with 5,398.78m2. A H144 management area was established in an annexed pavilion, where it was also placed the monitoring system for the hospital's environmental conditions (humidity, temperature, and $\mathrm{CO}_{2}$ ). From an architectural design point of view, ${ }^{11}$ some aspects that were taken into consideration were: (1) the feasibility of the chosen venue; (2) adaptation of the design to an existing structure; (3) the definition of spaces and work areas; (4) coordination between design and clinical aspects; and (5) comfort for patients and workers. The execution of the work was quite a logistical challenge, especially in the first wave, where the breakdown of stocks at the international level increased efforts in searching for material and companies that could carry out the work with certain standards of hospital quality. ${ }^{12}$ Among the many aspects that affected the implementation of the project were: (1) feasibility of the structural design; (2) patient and staff comfort and environmental safety; (3) market competitiveness, especially oxygen therapy; (4) coordination with clinical functional plan and availability of electromedicine; (5) the establishment of an adequate communications network; (6) waste management; (7) the management and availability of adequate supplies and flows (ie, energy, water, food, and linen); and (8) the implementation of a biosecurity plan. 


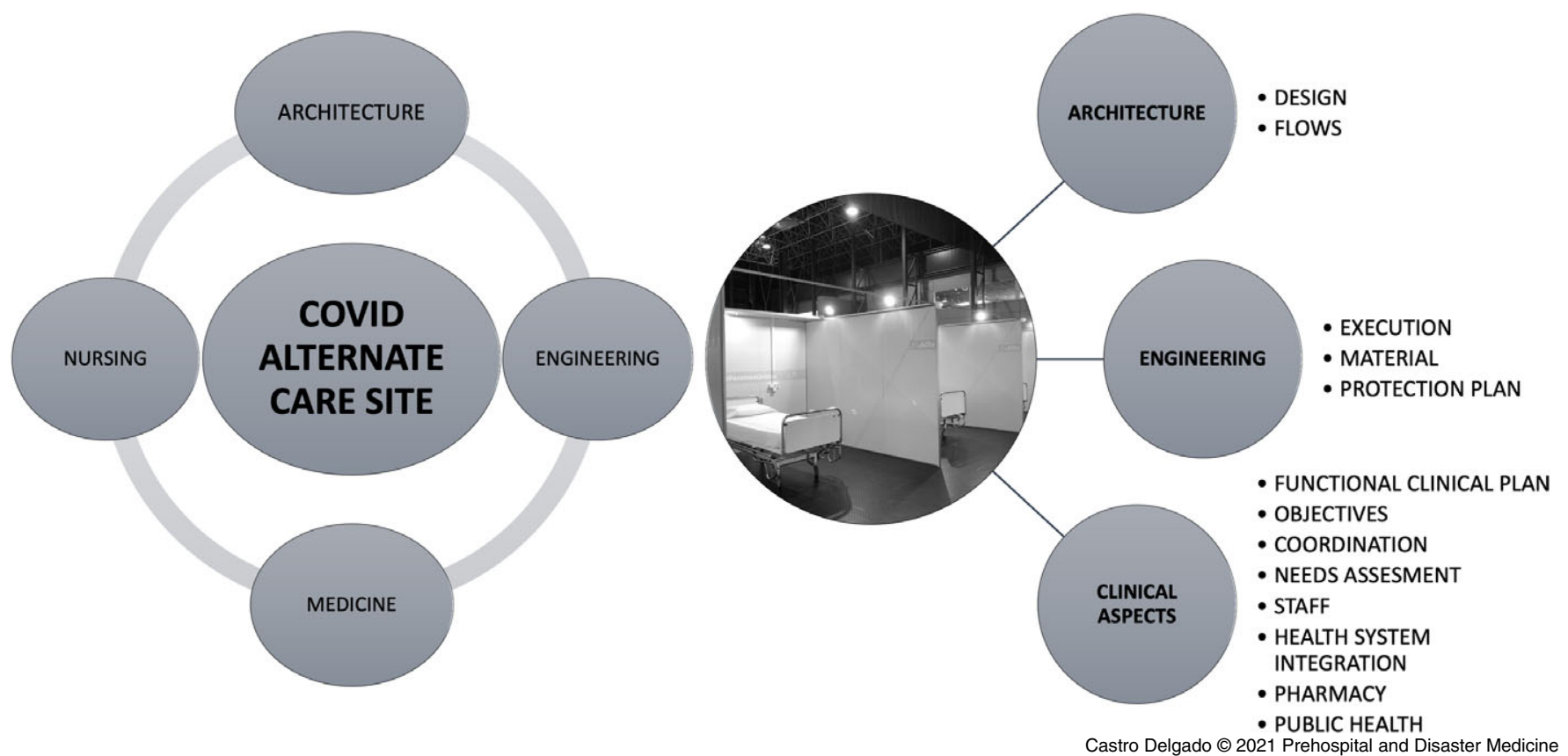

Figure 1. Different Fields of Knowledge Related to Health that Worked on the Project.

In the H144, three main work areas were defined (Figure 2):

1. COVID-19 (+) Patient Care Area: Six modules of 24 beds each (144 beds in total), with a nursing station per module. Rooms were individual, separated by panels of 2.7 meters high, and with a surface of nine square meters $(3 \times 3 \mathrm{~m})$, with a chair, a table, and an individual wardrobe. In this health care area, there was also a toilet and shower area, a reading/TV area, a triage area, a medical work room, and a warehouse area. A special room was also designed for relatives to accompany patients in a very severe condition, prior to death. It had two entrances: one from the inside for the patient and one from the outside for relatives.

2. Working Area: Without risk of contamination, with staff dressing rooms with lockers and showers, work area for doctors, and rest area.

3. Logistic Area: Without risk of contamination, with a general logistics warehouse, lingerie area, food preparation area, health material store, pharmacy, and management area. Outside, in an annex pavilion, there was a waiting room for relatives.

\section{Health Aspects in the Design and Implementation of the H144}

From a health point of view, multiple factors were taken into consideration, which were developed in parallel with the construction of the hospital.

Definition of Health Care Objectives-One of the keys of ACS for COVID-19 patients is a clear definition of their health care objectives, always taking into account the necessary flexibility in a changing reality. The H144 was designed to treat COVID-19 patients without or with moderate symptoms, and that in case of clinical worsening, would not be candidates for ICU admission due to poor functional and cognitive situations (Barthel index prior to acute illness $\leq 15) .{ }^{13}$ Only in the event that the regular hospital network could not admit more severe patients, these would be treated at the $\mathrm{H} 144$ with prior authorization from health authorities.
Design of a Humanization Plan ${ }^{14}$-Parallel to the design of the functional plan, a humanization plan was designed, including aspects such as reception and information plan for patients and relatives, welcome and training plan for staff, and a special approach for comfort care for terminally ill patients, including relatives visits in a specially designed room. In addition, an outdoor space was set up so that patients with a good clinical condition could go for a walk outside, accompanied by specific staff with appropriate use of personal protective equipment (PPE).

Definition of Flows and Work Areas - The first flow to be defined was the admission of patients. The COVID-19 coordinator of each hospital, usually a doctor, contacted the H144 medical direction to provide clinical information and ask for patient transfer. After checking the availability of beds and the adequate profile of the patient, the patient was admitted. Patients from nursing homes or from the primary health care network requiring hospital care or isolation could also be admitted, but always after blood test and thorax $x$-ray in the emergency department (Figure 3). The H144 received patients until 8:00PM every day of the week.

Waste Management Plan-Following regional law 22/2011 of waste and contaminated soil ${ }^{15}$ and the guide for the management of sanitary waste of the Principality of Asturias, ${ }^{16}$ a simple waste management plan was drawn up, dividing them into two large groups (non-hazardous and hazardous). In the white or green area, the waste would be classified as non-hazardous, with a subsequent division of these as recyclable or not, while all the waste generated in the red area would be classified as hazardous waste and would be sent to the incinerator for disposal.

Management of Human Resources and Training Program-Staff assigned to the H144 were mostly professionals from public health system job-seeker lists, to avoid absorbing health professionals from other centers. Training programs included a training session (operation and general structure of the H144, use of PPE, and the H144 emergency plan were addressed). 

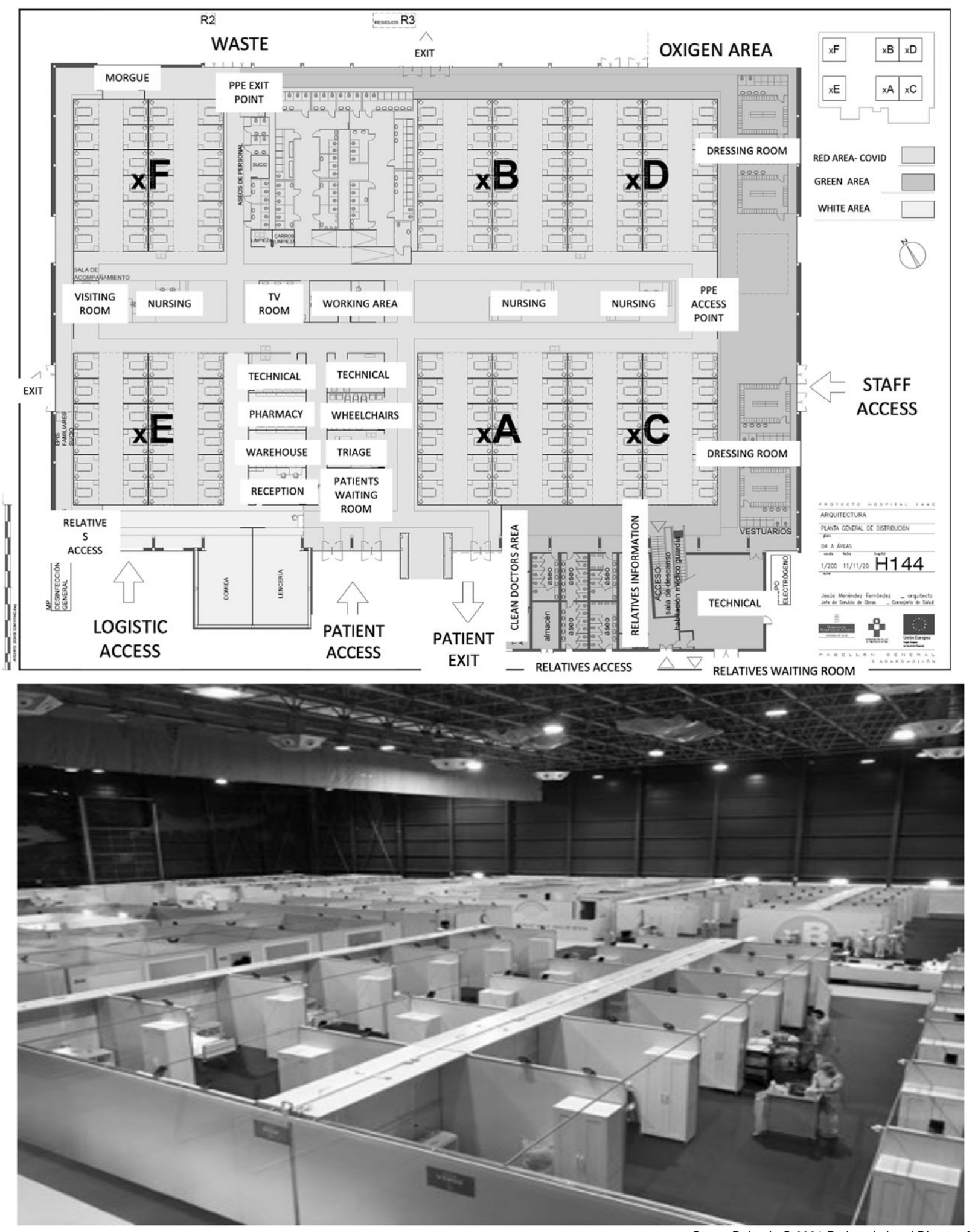

Figure 2. Main Work Areas Defined in the H144.

Castro Delgado @ 2021 Prehospital and Disaster Medicine Abbreviation: PPE, personal protective equipment.

Simulations were carried out to improve teamwork in emergency care in a contaminated area with PPE and to measure response time from the clean area. For the staff who carried out their entire working day with a PPE, a system of rest shifts was designed to plan 45-60 minutes breaks at least every three hours. Due to changing health care needs over the opening period, a system 


\begin{tabular}{|l|c|c|}
\hline Staff & Total Number & $\begin{array}{c}\text { Total per Shift per } \\
\text { 24 Patients Module }\end{array}$ \\
\hline Doctors & $3-9$ & 1 \\
\hline Nurses & $\begin{array}{l}\text { 12 Full Time + External } \\
\text { Paid Volunteers }\end{array}$ & 3 \\
\hline Nurse Assistant & $18-36$ & 3 \\
\hline Ancillary & $7-12$ & $4-6$ \\
\hline Administrative Staff & $2-3$ & 1 total \\
\hline Engineer & 2 & 2 total \\
\hline
\end{tabular}

Table 2. H144 Staff

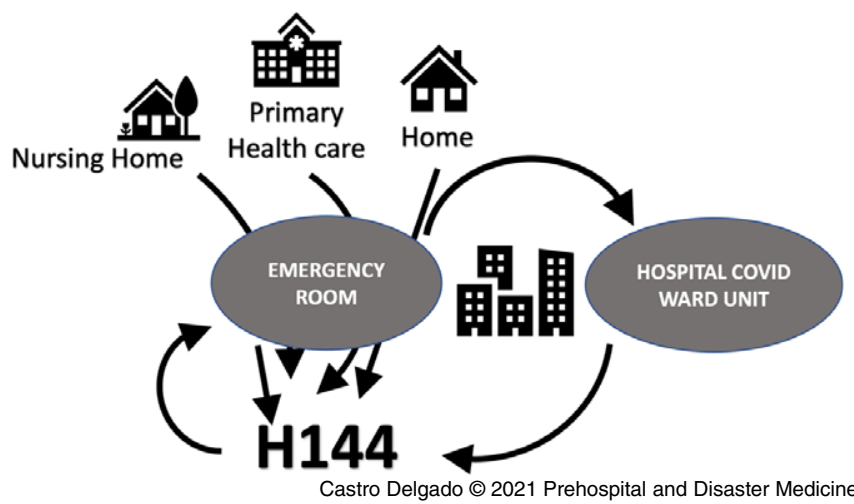

Figure 3. Locations Where Patients were Admitted From.

to open and close modules was designed in which external staff was activated to cover new needs when a new module was opened. Table 2 shows staff organization.

Coordination with Other Structures and Integration into the Public Health Care Network, Including Information Systems-Based on the H144 experience, the key to the success of ACS for COVID-19 patients is their correct integration into the health system network, at an organizational, technical, and "emotional" level. In this sense, it is essential that fixed hospitals feel these facilities as a resource to support their daily activity in caring for COVID-19 patients. This required multiple meetings to inform about the structure and operational aspects of H144, in addition to faceto-face visits by clinical managers before and during its operation. Although patients were received from the entire health system in Asturias, H144 was integrated into the logistics and technological circuits of the Cabueñes University Hospital (HUCAB) in Gijón, which made easy daily operation by using existing logistics circuits (ie, warehouse, pharmacy, kitchen, and lingerie). Sespa's Infrastructure and Technical Services was in charge of integrating H144 into Sespa's Electronic Health Record System, called SELENE, as an extension of HUCAB. For this, it was necessary to build up the entire hardware infrastructure in the center itself. In addition, templates, forms, reports, and ad-hoc requests were designed, which made it possible to have a specific software work scenario for $\mathrm{H} 144$, but integrated with $\mathrm{HUCAB}$, allowing to request and access to all the necessary tests, as well as to carry out consultations with other services, if necessary. Pharmacological prescriptions were also managed through SELENE, which were received daily in the form of single doses for each patient prepared by the pharmacy service. The integration was such that, when necessary, the presence of physiotherapists and psychologists from HUCAB was required in H144. Furthermore, coordination with the Social Work Unit was essential given the special social circumstances for a significant number of patients.

Biosecurity Plan-Processes were developed for cleaning and environmental disinfection, including surfaces and materials, to provide the highest level of biosafety for patients and professionals. Environmental control of air quality (particles of 0.5 and 5.0 $\mu \mathrm{m}$, humidity, temperature, and concentration of $\mathrm{CO}$ and $\mathrm{CO}_{2}$ ) was made, as well as count of aerobic flora in the environment in representative areas (analysis of general microbiological contamination and microbiological analysis to identify COVID-19). Also, bio-decontamination of areas, equipment, and material during the activity was performed with Ethylene peroxide, obtaining excellent results.

\section{Clinical Activity}

The H144 was opened from November 12, 2020 through March 5, 2021. A total of 334 patients were admitted, generating 3,149 hospital stays. A sequential opening-closing system of modules was established to adapt to the needs, planning human resources according to H144 activity. Maximum occupancy was on February 1, 2021 (74 patients). In Figure 4, it shows the daily number of patients admitted to the H144 compared to the patients admitted for COVID-19 in the Sespa hospital network. Number of patients follows the wave of hospital occupancy in both the second and third waves. Between both waves, a small health care activity was maintained due to the admission of patients from an outbreak in a nursing home. ${ }^{17}$

There was a total of 334 admissions (66\% women; $34 \%$ men), with a mean stay of 9.42 days $(\mathrm{MD}=3.99$; [1-34]), generating a total of 3,149 hospital stays. At discharge, 126 patients (38\%) went to a nursing home, 112 (33\%) to their home, 40 (12\%) were transferred to another hospital, and 56 (17\%) died. Of those transferred to the hospital, $31(77.5 \%)$ were admitted and did not return to the H144. The mean age of the admitted patients was 82.79 years $(\mathrm{MD}=8.68 ;$ [29-104]) and was higher in women (85.09; $\mathrm{MD}=7.57 ; \mathrm{P}=.000)$ than in men $(78.28 ; \mathrm{MD}=9.22)$, which could explain higher mortality among women ${ }^{18}(19.5 \%$ versus $11.5 \%$ in men), greater average stay ( 9.74 versus 8.81 in men), and higher discharge to nursing homes ( $41 \%$ versus $30 \%$ in men). Forty-three percent of men were discharged at home $(28 \%$ in the case of women). In Table 3, these differences are shown.

As mentioned above, the H144 supported Sespa's health structure. In Figure 5, the origin of the patients is shown.

From the medical point of view, patients were basically grouped into two categories: mild COVID-19 patients awaiting for recovery on one side, and on the other hand, moderate patients not candidates to intensive care measures in case of clinical worsening. Many of the first group of patients came from nursing homes. ${ }^{19}$ As they needed a negative COVID-19 polymerase chain reaction (PCR) test prior to be discharged to their nursing home, medical treatment tended to be simple, trying to prevent further complications (thrombosis, delirium, nosocomial infection, physical deconditioning, and malnutrition associated with hospitalization). ${ }^{20,21}$ For patients in the second category, symptomatic treatment, humanization of the stay, and palliative care were focused on. ${ }^{22}$ In all the patients, the main problem was the tendency to delirium and disorientation typical of hospital stay, increased due to a lack of circadian references for being in a facility without windows, and for 


\begin{tabular}{|l|c|c|c|c|}
\hline & Global & Female (66\%) & Male (34\%) & P Value \\
\hline Age [media (SD)] & $82.79(\mathrm{SD}=8.68)$ & $85.09(\mathrm{SD}=7.57)$ & $78.28(\mathrm{SD}=9.22)$ & .000 \\
\hline Stay [media (SD)] & $9.42(\mathrm{SD}=3.99)$ & $9.74(\mathrm{SD}=3.96)$ & $8.81(\mathrm{SD}=3.95)$ & .048 \\
\hline Mortality & $17 \%$ & $19.45 \%$ & $11.50 \%$ & .065 \\
\hline Discharge to Nursing Homes & $38 \%$ & $41.00 \%$ & $30.00 \%$ & .068 \\
\hline Discharge to Home & $33 \%$ & $28.50 \%$ & $43.36 \%$ & .006 \\
\hline Transferred to Other Hospitals & $12 \%$ & $10.85 \%$ & $14.15 \%$ & .37 \\
\hline
\end{tabular}

Table 3. Differences by Gender of the Patients

\section{COVID Patients in Asturias hospitals}

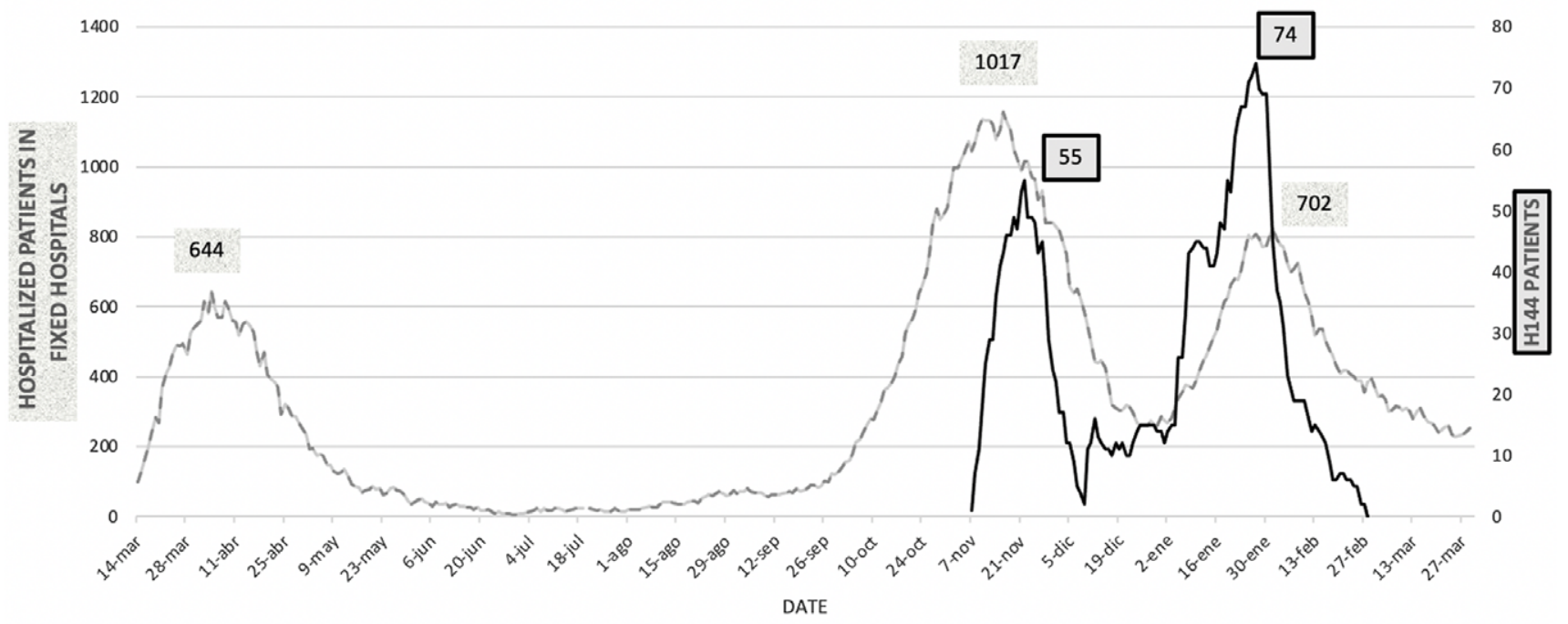

Figure 4. Daily Number of Patients Admitted to the H144 Compared to Patients Admitted for COVID-19 in Sespa's Hospital Network.

prolonged stays in patients with preserved cognitive status with persistently positive PCRs. ${ }^{23}$ In future similar experiences, it is suggested to be flexible with family visits, walks outside the hospital, and other measures to avoid delirium and physical deconditioning due to activity limitation. ${ }^{24,25}$ The physical structure of the hospital would be maintained and the distribution of staff in direct contact with the patient, as well as good coordination and teamwork among staff from diverse origins.

\section{Discussion}

From the H144 experience, the design, execution, and implementation of an ACS for COVID-19 patients is a challenge in which the participation of different areas of knowledge is essential. Among the aspects to consider for future ACS based on this experience, the following could be highlighted:

1. The concept of "temporary hospital" should not imply a decrease in hospital technical requirements or in terms of quality of care.
2. A multidisciplinary team, well cohesive and motivated, with common objectives and the ability to adapt to changing environments is one of the critical aspects, probably for any complex project.

3. The team that designs the facility and its functional plan must be the same as the one in charge of the facility during its activity.

4. Support and acceptance of the rest of the health care network is essential for the success of the project. All must work in coordination with the rest of the health care structures, accept external suggestions for improvement, and work with the clear conviction that it is a health facility to serve the rest of the health care system and, lastly, the citizens. Communication must be fluid and permanent throughout the entire period of operation.

5. Permanent adaptability of all equipment and structure is necessary. During the operation period, various scenarios, not foreseen in the initial functional plan, were contemplated (ie, possibility of admitting asymptomatic patients for 


\section{Origin of $\mathrm{H} 144$ patients}

250

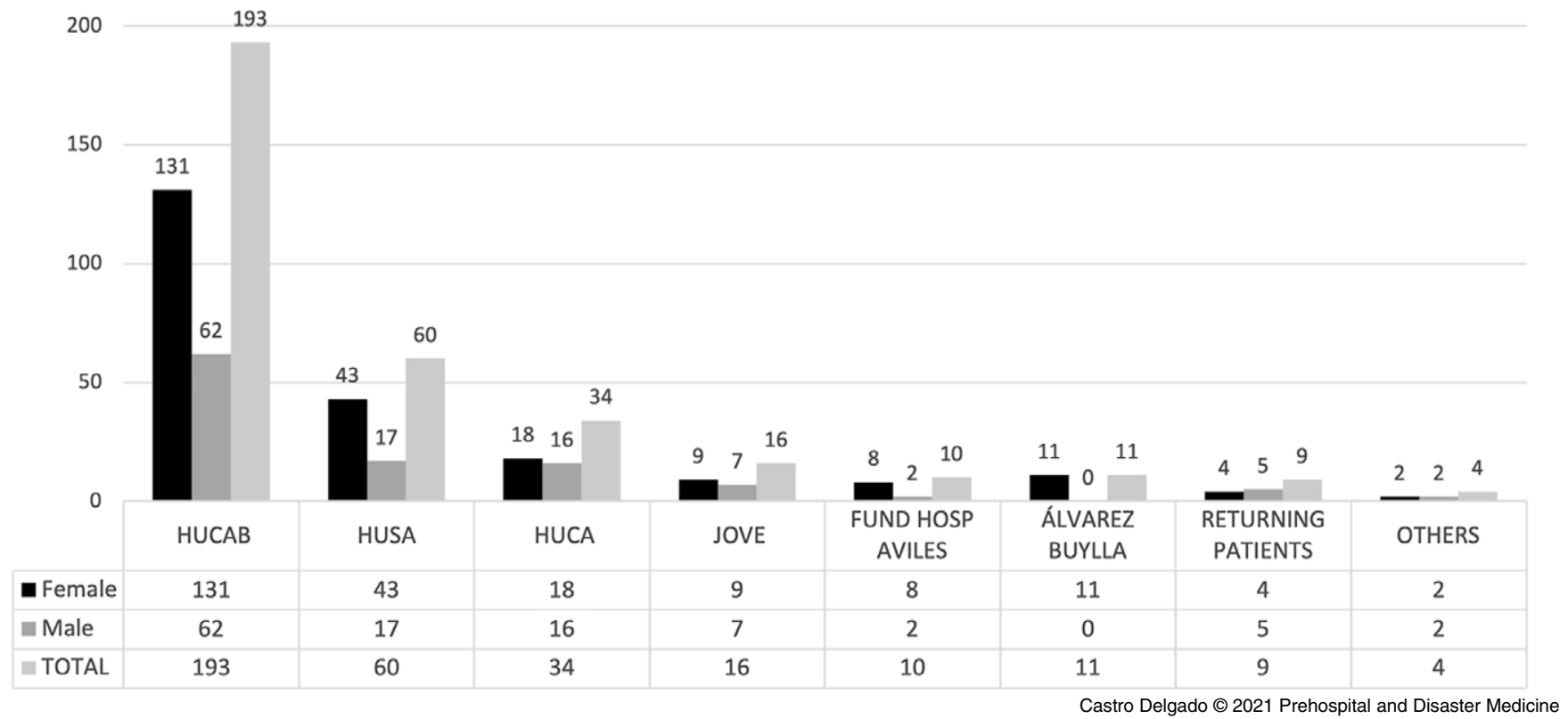

Figure 5. Origin of Patients.

Abbreviations: HUCAB, Cabueñes University Hospital; HUSA, Hospital Universitario San Agustín; HUCA, Hospital Universitario Central de Asturias; JOVE, Hospital de Jove.

isolation, and use of non-invasive ventilation not considered initially). The architectural and functional design of the H144 allowed for the contemplation of multiple organizational and health care approaches.

6. The fact of opening and closing modules sequentially according to needs was a challenge from the point of view of staff organization, and even so, maintaining the staff ratios initially designed was managed. The main difficulty was precisely this: get staff under the premise of not reducing resources in other health care facilities.

7. Team building activities must be developed from the very beginning of the project, facilitating two-way communication with the management team and allowing the implementation of improvement proposals. ${ }^{26}$

8. The success of $\mathrm{H} 144$ would not have been possible without its Humanization Plan. Only an approach from the humanization of care could relieve the fears of patients, relatives, and workers facing an unknown situation. In the same way, accompaniment in the dying process facilitates mourning. Communication with the relatives was essential, providing permanent communication with them. Probably, H144 patients were the only COVID-19 patients admitted to a hospital who had the possibility to walk outside.

\section{Limitations}

As a main limitation of this report, this experience was developed in a country with a well-develop public health care system, so the aspects proposed to consider for future experiences must be taken into consideration for similar contexts, or in some cases, adapted to different ones. Also, clinical follow-up of the patients after discharge was not made, as it was beyond the objectives of this report, but could be of interest for future research.

\section{Conclusion}

Alternate care sites for COVID-19 patients can be valuable health care structures to improve surge capacity of the health system when overwhelmed with COVID-19 patients. For that purpose, they need to be well-designed and integrated into the health care network. Focusing ACS on mild patients allows hospitals to focus on more severe patients, avoiding that these structures "absorbed" specialized staff from other more complex hospitals, and may also have positive effects on the control of epidemic outbreaks in nursing homes. The results and experience of use of the H144 Hospital of the Health Service of the Principality of Asturias was satisfactory for the patients and the health system.

\section{Acknowledgments}

The authors wish to acknowledge: Jesús Menéndez, architect of the Health Authority in charge of the architectural project; All Health Authority departments involved in the design and implementation of the H144 hospital; All H144 health care and non-health care workers who were somehow linked to this project; The families, for their enormous understanding of everything that could be improved; and of course, The patients, to those alive and to those who left, for teaching all to be better professionals. 
References

1. Klein MG, Cheng CJ, Lii E, et al. COVID-19 models for hospital surge capacity planning: a systematic review. Disaster Med Public Health Prep. 2020. Epub ahead of print.

2. World Health Organization. Department of Emergency and Humanitarian Action. WHO-PAHO Guidelines for the Use of Foreign Field Hospitals in the Aftermath of Sudden-Impact Disasters. 2003. https://iris.paho.org/handle/10665.2/40820. Accessed August 6, 2020.

3. Federal Healthcare Resilience Task Force Alternate Care Site Toolkit Second Edition. https://files.asprtracie.hhs.gov/documents/acs-toolkit-ed1-20200330-1022. pdf. Accessed April 24, 2020.

4. Community Facilities for Preparedness and Response to COVID-19. Isolation, treatment, and step down of COVID-19 cases in community facilities: a scalable, modular, and temporary solution based on the Emergency Medical Team methodology. Emergency Medical Teams Initiative. World Health Organization; 2020. https:// extranet.who.int/emt/guidelines-and-publications. Accessed August 6, 2021.

5. Severe Acute Respiratory Infections Treatment Center. Practical manual to set up and manage a SARI treatment center and SARI screening facility in health care facilities. World Health Organization; 2020. https://extranet.who.int/emt/guidelines-andpublications. Accessed August 6, 2021.

6. Candel FJ, Canora J, Zapatero A, et al. Temporary hospitals in times of the COVID pandemic. An example and a practical view. Rev Esp Quimioter. 2021; 34(4):280-288.

7. Sacchetto D, Raviolo M, Beltrando C, Tommasoni N. COVID-19 surge capacity solutions: our experience of converting a concert hall into a temporary hospital for mild and moderate COVID-19 patients. Disaster Med Public Health Prep. 2020. Epub ahead of print.

8. Meyer GS, Blanchfield BB, Bohmer RMJ, Mountford J, Vanderwagen C. Alternative care sites for the Covid-19 pandemic: the early US and UK experience. NEJM Catalyst Innovations in Care Delivery. 2020.

9. Bouza E, Pérez-Granda MJ, Escribano P, et al; Senex-COVID-19 Study Group. Outbreak of COVID-19 in a nursing home in Madrid. J Infect. 2020;81(4):647-679.

10. Memoria SESPA 2017. https://www.astursalud.es/documents/31867/563250/ MEMORIA+SESPA+2017.pdf/aee72d8b-e9e2-1aa1-b071-b7833b19c2ce. Accessed August 6, 2021.

11. Pernas Gali F. La “arquitectura” del COVID. Anuario 2020 de la Asociación Española de Ingeniería Hospitalaria. https://aeih.org/wp-content/uploads/2020/10/AEIHAnuario-2020.pdf. Accessed August 6, 2021.

12. Ministerio de Sanidad y Política Social. Estándares y recomendaciones de calidad de las unidades asistenciales. https://www.mscbs.gob.es/organizacion/sns/planCalidadSNS/ EEyRR_org.htm. Accessed August 6, 2021.

13. Consejería de Salud y Consejería de Servicios Sociales del Principado de Asturias. Circuito específico para pacientes COVID19 en centros sociosanitarios. Criterios clínicos de clasificación de pacientes y niveles de atención (Versión 4.0. Actualizado a 20 de Noviembre de 2020). https://www.astursalud.es/documents/31867/986714/
Circuito + especifico + para + pacientes+COVID19+en+centros+sociosantiario_30 11_2020.pdf/760d6614-78a9-9146-9030-805a29dea668. Accessed August 6, 2021. 14. Observatorio de Salud en Asturias. Dirección General de Salud Pública. Consejería de Sanidad del Principado de Asturias. Plan de Salud del Principado de Asturias 20192030: Poblaciones Sanas Personas Sanas. Oviedo, 2019. https://www.astursalud.es/ documents/31867/223830/Plan+de+Salud+del+Principado+de+Asturias+2019_ 2030.pdf/7b49d08e-fef0-6b9f-a3b0-61a1bfa320bd?version=1.0. Accessed August 6, 2021.

15. Ley 22/2011, de 28 de Julio, de residuos y suelos contaminados. BOE núm. 181, de 29/ 07/2011. https://www.boe.es/buscar/act.php?id=BOE-A-2011-13046. Accessed August 6, 2021.

16. Servicio de Salud del Principado de Asturias. Consejería de Salud. Guía para la gestión de residuos sanitarios del Principado de Asturias. Oviedo, 2014. https://www. astursalud.es/documents/31867/36150/Guia+Residuos+Sanitarios.pdf/cb834a6d21dd-d000-09ef-ef2b77657ec6. Accessed August 6, 2021.

17. Mas Romero M, Avendaño Céspedes A, Tabernero Sahuquillo MT, et al. COVID-19 outbreak in long-term care facilities from Spain. Many lessons to learn. PLoS One. 2020;15(10):e0241030.

18. Bonanad C, García-Blas S, Tarazona-Santabalbina F, et al. The effect of age on mortality in patients with COVID-19: a meta-analysis with 611,583 subjects. J Am Med Dir Assoc. 2020;21(7):915-918.

19. Gallego VM, Codorniu JM, Cabrero GR. The impact of COVID-19 on the elderly dependent population in Spain with special reference to the residential care sector. Cien Saude Colet. 2021;26(1):159-168.

20. Centro de Coordinación de Alertas y Emergencias Sanitarias. Dirección General de Salud Pública, Calidad e Innovación. Ministerio de Sanidad. Documento técnico Manejo clínico del COVID-19: atención hospitalaria 918 de Junio de 20209. https:// www.mscbs.gob.es/profesionales/saludPublica/ccayes/alertasActual/nCov/documentos/ Protocolo_manejo_clinico_ah_COVID-19.pdf. Accessed August 6, 2021.

21. Inouye SK, Bogardus ST Jr, Charpentier PA, et al. A multicomponent intervention to prevent delirium in hospitalized older patients. N Engl J Med. 1999;340(9):669-676.

22. Fadul N, Elsayem AF, Bruera E. Integration of palliative care into COVID-19 pandemic planning. BMJ Support Palliat Care. 2021;11(1):40-44.

23. Guilcher SJT, Everall AC, Cadel L, Li J, Kuluski K. A qualitative study exploring the lived experiences of deconditioning in hospital in Ontario, Canada. BMC Geriatr. 2021;21(1):169.

24. Zisberg A, Shadmi E, Sinoff G, Gur-Yaish N, Srulovici E, Admi H. Low mobility during hospitalization and functional decline in older adults. $\mathrm{J} \mathrm{Am} \mathrm{Geriatr} \mathrm{Soc.}$ 2011;59(2):266-273.

25. Hoyer EH, Friedman M, Lavezza A, et al. Promoting mobility and reducing length of stay in hospitalized general medicine patients: a quality-improvement project. $J$ Hosp Med. 2016;11(5):341-347.

26. Miller CJ, Kim B, Silverman A, Bauer MS. A systematic review of team-building interventions in non-acute healthcare settings. BMC Health Serv Res. 2018;18(1):146. 